\title{
Decent Work, Work Motivation, Work Engagement and Burnout in Physicians
}

\section{Tânia Ferraro ${ }^{1}$ (1) - Nuno Rebelo dos Santos ${ }^{2}$ (1) - João Manuel Moreira ${ }^{3}$ (1) Leonor Pais ${ }^{1}$ (D)}

Accepted: 2 December 2019 / Published online: 20 January 2020

(C) Springer Nature Switzerland AG 2020

\begin{abstract}
This article presents the relationships among decent work (DW; Decent Work Questionnaire), work motivation (Multidimensional Work Motivation Scale), work engagement (Utrecht Work Engagement Scale) and personal-burnout (subscale of Copenhagen Burnout Inventory) in Portuguese and Brazilian physicians $(N=605)$. Canonical correlation analyses were performed. The results in the Portuguese sample: the seven DW factors were related to identified and intrinsic-work-motivation, work-engagement and less personal-burnout. Adequate-working-time-and-workload is associated with decreases of identified-work-motivation and personal-burnout. Less meaningful-remuneration-forthe-exercise-of-citizenship is related to less extrinsic-material-work-motivation and extrinsic-social-work-motivation; in the Brazilian sample: fundamental-principles-and-valuesat-work, adequate-working-time-and-workload, fulfilling-and-productive-work, and opportunities relate to identified and intrinsic-work-motivation, work-engagement, less amotivation and less personal-burnout. Less adequate-working-time-and-workload and less social-protection are associated with more personal-burnout. In both samples, the DW global score were related significantly and positively with the more self-determined types of work-motivation (intrinsic and identified); and significantly and negatively with the amotivation. These results help human resources management to enhance physicians' performance and well-being, and therefore the quality of care provided.
\end{abstract}

Keywords Decent work questionnaire - Work-motivation · Work-engagement · Personalburnout $\cdot$ Knowledge workers $\cdot$ Canonical correlations $\cdot$ Cross-cultural study

\section{Introduction}

The present research aims to study the relationship between decent work (DW; International Labour Organization 1999), work-motivation (Gagné and Deci 2005),

Tânia Ferraro

taniaferraro@gmail.com

Extended author information available on the last page of the article 
work-engagement (Schaufeli et al. 2002b) and personal-burnout (Kristensen et al. 2005). The DW concept was proposed by the International Labour Organization (ILO) in 1999, and is the result of a long journey involving the ILO and the United Nations (UN; Ferraro et al. 2016; International Labour Organization 1944, International Labour Organization 1999; Treaty of Versailles 1919; UN 2000, 2015).

The huge changes witnessed in the realm of work have highlighted the relevance of the DW concept. Workers' approach and experience regarding their own work (and to what extent a DW deficit is present) might point out new aspects that have been disregarded by the more traditional approaches to that concept. This paper contributes to filling this gap through research from the work, organizational and personnel psychology (WOPP) perspective.

Some measures of workers' perception of DW were developed recently (Ferraro et al. 2018b; Webster et al. 2016). In the present research we approach DW as conceptualized and measured by Ferraro et al. (2018b). They have shown a Global DW factor and seven specific factors: a) Fundamental Principles and Values at Work; b) Adequate Working Time and Workload; c) Fulfilling and Productive Work; d) Meaningful remuneration for the exercise of citizenship; e) Social Protection; f) Opportunities, and g) Health and Safety.

We report on research aiming to study the relationships between DW and work motivation (WM), work-engagement and burnout in physicians. Previous research suggests that DW conditions relate to WM (Ferraro et al. 2018a). Furthermore, workengagement has been shown to be positively related to work performance, organizational effectiveness and workers' well-being. Burnout is negatively related to the same variables (Baard et al. 2004; Cropanzano et al. 2003; Milfont et al. 2008; Schaufeli et al. 2002b).

\subsection{Physicians' Professional Context}

Considering that physicians have specific work characteristics where interpersonal issues, high responsibility and new knowledge are always challenges they have to deal with in their daily professional duties, it will be interesting to understand the specific dimensions of DW related to WM, work-engagement and burnout. Physicians' work is characterized by complex, critical, fast and/or interactive ethical decision-making processes that involve health and illness, life, death, and serious consequences (Bowden et al. 2015). A broad range of challenges, potential stressors and rewards characterize the occupational environments of physicians (Arnetz 2001). Some of those "are intrinsic to medical practice, such as working with emotionally intense issues, suffering, fear, sexuality, failures, and death" (Arnetz 2001, p. 2005). Although their work depends on good relationships within the team and with healthcare management, they have several workgroups and workplaces due to the scheduling practices of the physician profession leading to a "sense of being out of the organization" (Lindgren et al. 2013, p. e154). McAlearney et al. (2005) affirm that physicians are developed in a medical culture that prepares them to take autonomous decisions, apply a reactive approach to problem solving and maintain a focus on individual patients. Considering the physician' health, Arnetz (2001) refers to a "triple sign of the 'ignorance, indifference, and carelessness' of physicians toward their own health" (p. 204). Other aspects associated with work in a healthcare workplace may contribute to this. Physicians work 
in a healthcare environment and this could make them pay less attention to their own health, safety or social protection. Additionally, they have "considerable power and influence in healthcare development processes and practices" (Lindgren et al. 2013, p. e139), which could create a belief/expectation that since they are more protected than others they do not need to be concerned about their own health.

Among the negative characteristics of this profession, Arnetz (2001) adds sleep deprivation, fatigue and long working hours. These specificities ultimately differentiate them from other types of knowledge workers (KW) and justify our study. It will be helpful for human resource (HR) management in healthcare to know the key-aspects of this profession which are shown to be crucial in determining positive outputs both for individuals and organizations.

According to Mládková et al. (2015) the work-motivation of KW in general is understudied. Investigation of the WM of specific professional groups of KW is also scarce, albeit with a little more development. This is the case of WM in health professionals (Mathauer and Imhoff 2006; Misfeldt et al. 2014; Rowe et al. 2005; Willis-Shattuck et al. 2008) and in particular physicians, as was synthesized in the literature review by Nantha (2013). Application of the DW concept to this professional group seems to be particularly timely, especially taking into account the state of health systems and the frequent studies that show professional burnout in health care workers (Borritz et al. 2006) and specifically in physicians (Kamal et al. 2016; Kassam et al. 2015). The study of physicians' motivation could also promote deepen understanding of the balance point between the inner satisfaction of physicians and better healthcare workplace efficiency and the efficacy of healthcare systems (Nantha 2013).

\subsection{Work Motivation (Self-Determination Theory, SDT)}

The SDT was proposed to elucidate the optimal human motivation in different life domains and its contribution to different positive outcomes such as performance at work, personal development and growth, resilience and well-being (Sheldon and Ryan 2011). Gagné and Vansteenkiste (2013) consider that "SDT is a theory of positive psychology because it focuses on how to promote optimal human functioning” (p. 76). Those positive outcomes applied to workplaces are studied in different approaches of Positive Psychology: Positive Organizational Behavior (Luthans 2002a, b; Luthans and Avolio 2009; Luthans and Youssef 2007; Wright 2003) and Positive Organizational Scholarship (Bakker and Schaufeli 2008; Cameron and Caza 2004); among others.

In the present study, we adopt SDT to investigate different types of work-motivation along a self-determination continuum from amotivation to intrinsic motivation (Gagné and Deci 2005). They are regulated by different types of behavior that represent levels of autonomous motivation. The work-motivation continuum is composed of amotivation (lack of motivation); extrinsic-material-regulation based on the material consequences of work (e.g. salary); extrinsic-social-regulation (WM based on the pursuit of positive appraisal, such as compliment or praise). In both situations, avoidance of external punishments is also included. Introjected WM anchored in an inner pressure to accomplish work associated with feelings of obligation or guilt; identified WM, when the work is done for identification with its value or meaning; and, intrinsic WM, when work is done for interest and pleasure (Gagné et al. 2015). 


\subsection{Well-Being at Work: Work Engagement and Burnout}

Well-being at work is also relevant for understanding physicians' work behavior. Schaufeli et al. (2002b) affirm that the concepts of work-engagement and burnout are facets of well-being at work. They state that "conceptually speaking, engagement is the positive antithesis of burnout", but that "the measurement of both concepts, and hence its structure, differs" (p. 75). This justified creation of the Utrecht Work Engagement Scale (UWES; see also Maslach et al. 2008). This school of thought considers that work-engagement is a distinct, independent concept negatively related to burnout (Bakker et al. 2014), with different predictors and consequences (Schaufeli and Bakker 2004). Additionally, burnout seems to be more related to health problems and work-engagement to motivational states (Schaufeli and Bakker 2004). Workengagement can be defined as an affective-emotional work-related state of mind of positivity and fulfillment with three principal characteristics: vigor, dedication, and absorption (Schaufeli et al. 2002b). Work-engagement is based on the idea that the worker can feel high levels of vigor, dedication and absorption at work and can be included in the field of positive organizational behavior (Bakker and Schaufeli 2008). Vigor expresses professional mental resilience and levels of energy while working. Dedication represents strong involvement with the job and experiencing significance, challenge, inspiration, pride and enthusiasm assigned to work. Absorption refers to concentration and the sense of absorption at work. The worker who feels and produces with work-engagement (Bakker et al. 2008; Schaufeli et al. 2008), beyond enthusiasm about their own work, does not show compulsion drive or addiction (this is the case of workaholism and is intrinsically negative; Caesens et al. 2014). Work-engagement and workaholism have in common the tendency to work hard, but represent different psychological states (Caesens et al. 2014). Work-engagement might become workaholism and exhaustion (emotional and physical) through overload, as in burnout. In the present study, we do not explore the relationships around workaholism (Schaufeli et al. 2013). According to these authors, work-engagement is achieved when despite job pressures and stress or facing repetitive, monotonous or boring tasks, the worker likes what (s)he is doing, feels challenged and enthusiastic about the work itself, and is able to balance exciting and enriched tasks adequately (Schaufeli et al. 2013).

Despite several points of view (Schaufeli and Taris 2005), burnout is commonly associated with high emotional load, which often happens in human service professions (Kristensen et al. 2005). Considering our sample, physicians' job/work is nearly always performed within a team, it is fundamentally designed with the ultimate goal of caring for people, and involves life, health, illness and death issues. This makes the physicians' professional group potential 'candidates' for burnout, which has been shown in many studies (Anagnostopoulos et al. 2012; Garcia et al. 2015; Schaufeli et al. 2011; Shirom et al. 2006). Physician burnout is of high social relevance because besides jeopardizing the health of the doctor himself/herself, it may have serious consequences for patient health and safety (Wen et al. 2016) and could also be associated with the intention to leave the job, threatening the effectiveness of healthcare (Prins et al. 2007; Shanafelt et al. 2010).

In a previous study on workers in general, Rodrigues (2018) found positive significant correlations between more autonomous regulation (identified and intrinsic WM) and two DW dimensions which were under scrutiny, namely (1) Fundamental 
Principles and Values at Work and (2) Opportunities. Casqueira (2018) went further and verified in the same sample that all DW dimensions correlated positively with intrinsic and identified WM, and negatively with amotivation. Considering the results found previously (Rodrigues 2018; Casqueira 2018), which show significant correlations between all DW dimensions and autonomous WM (identified and intrinsic; positive) and amotivation (negative), the DW global score is expected to correlate positively with more autonomous WM (identified and intrinsic) and negatively with the lack of any kind of motivation (amotivation). Therefore, in the present study we state that:

Global DW would correlate (H1) positively with the more self-determined types of work-motivation (intrinsic and identified); and (H2) negatively with the lack of workmotivation (amotivation).

DW as conceptualized by Ferraro et al. (2018b) refers to the design, content, context and consequences of work. Through canonical correlations Ferraro et al. (2018a) found two main mechanisms linking DW to work-motivation in knowledge worker samples (from Portugal and Brazil). The first mechanism associated with more psychological work motivations (intrinsic WM), included 'Fulfilling and Productive Work' (DW3), 'Fundamental Principles and Values at Work' (DW1) and 'Opportunities' (DW6) for the Portuguese sample. The Brazilian sample did not include DW6. These DW dimensions were positively associated with 'intrinsic and identified WM' and negatively related to 'amotivation' (in both samples).

In the second mechanism presented by Ferraro et al. (2018a), 'Social Protection' (DW5) was only included in the Portuguese sample. The Brazilian sample included 'Social Protection' (DW5) and in an opposite way 'Health and Safety' (DW7) among DW dimensions. This canonical correlation seems be more related to economic motivations (expressed by extrinsic-material WM) but also highlighted some kind of trade-off between high 'Social Protection' (DW5) and low compensation through extrinsic-material WM, for the Portuguese sample. In other words, 'Social Protection' was negatively related to 'extrinsic material WM'. For the Brazilian sample, this mechanism also included low 'Health and Safety' (DW7) between DW factors. That is, 'Social Protection' was also negatively related to 'extrinsic material WM' and 'Health and Safety' was positively associated with 'extrinsic material WM'.

Also with the application of canonical correlations analysis Ferraro et al. (2017) found among Portuguese and Brazilian lawyers two distinct processes (or mechanisms) which describe the relations between DW and work-motivation (WM). They called the first one 'decent working life as part of being a citizen in society' and the second one 'comfortable living situation and committed effort'. Included in the first process (with a Portuguese sample) are 'Fulfilling and Productive Work' (DW3), 'Opportunities' (DW6), 'Fundamental Principles and Values at Work' (DW1) and 'Meaningful Remuneration for the Exercise of Citizenship' (DW4). These DW dimensions were interpreted as influencing positively 'intrinsic and identified WM' and negatively 'amotivation'. A second sample (Brazilian) reproduced this result in spite of a slight difference found (the presence of 'Adequate Working Time and Workload' among the DW set of variables).

The second process described by those authors (Ferraro et al. 2017) includes in the Portuguese sample 'Adequate Working Time and Workload' (DW2), 'Social Protection' (DW5) and 'Meaningful Remuneration for the exercise of Citizenship' (DW4). In the Brazilian sample the canonical variates only include DW2 among the DW 
dimensions. For the Portuguese lawyers, the presence of those three DW factors was negatively related to 'extrinsic material WM' whereas for the Brazilian lawyers social extrinsic WM was also found to be negatively related.

Taking into account those results, it seems relevant to include other variables in the canonical correlations to verify to what extent similar or distinct mechanisms are found among physicians. As argued above, work-engagement and burnout are appropriate here.

The self-determination approach proposes that competence, autonomy and relatedness are essential needs that, when experienced, promote motivation development from lack of intentional regulation (or amotivation) to higher levels of autonomous motivation. Considering physicians' professional activity and given that the self-determination perspective postulated a major role of autonomy and relatedness (e.g., communication, interaction among people) in promoting autonomous motivation, we expect that DW factors more related to professional relationships in the job content (Fundamental-principles-and-values-at-work; Adequate-working-time-and-workload), and more related to autonomy and development (Fulfilling-and-productive-work; and Opportunities) will play an important role in outcome variables such as autonomous regulation (intrinsic and identified WM) and well-being variables (work-engagement and burnout).

More arguments can be added to reinforce the link mentioned. Lindgren et al. (2013) argue that professional fulfillment emerged as "a continual motivational drive in physicians' everyday working lives and in their career decision-making, affecting both their clinical engagement and healthcare development engagement" (p. e143). They highlighted that "professional learning and progress seem to lie at the heart of professional fulfilment" (Lindgren et al. 2013, p. e153). In our study, that can be reflected in the Fulfilling-and-productive-work and opportunities factors of DW. A physician's career development often depends on their updated expertise (McAlearney et al. 2005). This leads to permanent efforts for development.

Considering also physicians as a professional group focused on their patients' health and suffering, their own 'health-and-safety' and 'social-protection' have probably less direct influence over WM. Above all, physicians work in health and safety and they are an important element of others' social protection. They are trained to maintain a patientcentric focus (McAlearney et al. 2005). Because of this, these aspects of DW could be neglected by physicians. Therefore, we do not expect those DW factors to play a relevant role in predicting autonomous WM (intrinsic and identified) and well-being.

Better understanding of the contribution of DW deficit to burnout, work-engagement and work-motivation is relevant to improve physicians' performance and well-being, and therefore the quality of care provided.

\section{Method}

\subsection{Participants}

Our sample is composed of $\mathrm{KW}$, in particular, physicians of different specialities in Portugal $(n=300)$ and Brazil $(n=305)$. Data collection took place between August 2015 and July 2016, in a research project focused on the work experience of KW. 
The criteria for participation in the research were: a) at least six months' professional experience; b) currently employed; and c) receiving payment for the work done.

In the Portuguese sample, the percentage of women was $61.3 \%$ and, in the Brazilian sample 39.3\%. We show five categories of participants' age, each spanning 15 years. Both samples' distribution is presented in Table 1.

Considering the structure of the educational system in each country, we classified Level of Schooling in four categories. As expected, given the goals of sample recruitment, Table 1 also shows the predominance of participants with non-Ph.D. or Ph.D. levels of postgraduate education.

Sample recruitment was through professional associations, and when no professional associations were found, through institutional websites where professionals' email addresses were identified. Contact with associations or individual professionals was made personally, either by phone or by email. We summarized the study and presented the informed consent document and the survey. All participants were encouraged to express any questions or doubts (personally, by phone or by email). All participation was online. The participants were informed that they could terminate participation at any time. We assured anonymity, confidentiality and use of the results only for research purposes. Participants needed around 20 min to complete the task.

\subsection{Instruments}

\subsubsection{Decent Work Questionnaire (DWQ)}

The Decent Work Questionnaire (Ferraro et al. 2018b) is designed to measure decent work conditions from the perspective of workers. The validation study for Portuguese and Brazilian populations was presented in Ferraro et al. (2018b). With its 31items, the DWQ provides both a global DW score and seven subscale scores: Fundamentalprinciples-and-values-at-work (DW1), Adequate-working-time-and-workload (DW2),

Table 1 Demographic Characteristics of Participants $(N=605)$

\begin{tabular}{lll}
\hline Characteristics & $\begin{array}{l}\text { Portuguese Sample } \\
(n=300)\end{array}$ & $\begin{array}{l}\text { Brazilian Sample } \\
(n=305)\end{array}$ \\
\hline Age (years) & $142(47.3 \%)$ & $56(18.4 \%)$ \\
$21-35$ & $84(28 \%)$ & $124(40.7 \%)$ \\
$36-50$ & $69(23 \%)$ & $106(34.8 \%)$ \\
$51-65$ & $3(1 \%)$ & $16(5.1 \%)$ \\
$66-80$ & $2(0.7 \%)$ & $1(0.3 \%)$ \\
$\geq 81$ & $0(0 \%)$ & $2(0.7 \%)$ \\
Missing value & & $36(11.8 \%)$ \\
Highest Educational level & $17(5.6 \%)$ & $153(50.2 \%)$ \\
College degree / Bachelor or equivalent & $242(80.7 \%)$ & $109(35.7 \%)$ \\
Master degree and/or post-graduation or equivalent & $38(12.7 \%)$ & $7(2.3 \%)$ \\
PhD & $3(1 \%)$ & \\
Post-PhD & & \\
\hline
\end{tabular}


Fulfilling-and-productive-work (DW3), Meaningful-remuneration-for-the-exercise-ofcitizenship (DW4), Social-protection (DW5), Opportunities (DW6), and Health-andsafety (DW7). Responses to the DWQ are given on a 5-point Likert scale from 1= "I do not agree" to $5=$ "I completely agree". One sample item is "I consider the work I do as decent'. In the current study, the Cronbach alpha coefficient was .93 in the Portuguese sample, and .92 in the Brazilian sample. The subscales' alpha coefficients for DW in the Portuguese sample were: .86 (DW1), .85 (DW2), .81 (DW3), .88 (DW4), 75 (DW5), 74 (DW6) and .83 (DW7); in the Brazilian sample: .83 (DW1), .84 (DW2), .81 (DW3), .88 (DW4), .85 (DW5), .65 (DW6) and .83 (DW7).

\subsubsection{Multidimensional Work Motivation Scale (MWMS)}

The Multidimensional Work Motivation Scale (Gagné et al. 2015) measures different types of work-motivation, based on self-determination theory (Gagné and Deci 2005). In the current study we used the previously adapted and validated Portuguese and Brazilian versions (Dos Santos et al. 2018). The MWMS is a 19-item scale with six subscales: amotivation, extrinsic-material-regulation, extrinsic-social-regulation, introjected-regulation, identified-regulation and intrinsic-motivation. Responses to the MWMS are given on a 7-point Likert scale from $1=$ 'not at all' to $7=$ 'completely'. A sample item is 'Because I personally consider it important to put efforts into this job' following the stem 'Why do you or would you put efforts into your current job?' The six subscales' Cronbach alpha coefficients in the Portuguese sample were: .81 (amotivation), .78 (extrinsic-material-motivation), .87 (extrinsic-social-motivation), .80 (introjected-regulation), .89 (identified-regulation), and .89 (intrinsic-regulation); in the Brazilian sample were: .85 (amotivation), .83 (extrinsic-material-motivation), .88 (extrinsic-social-motivation), .80 (introjected-regulation), .83 (identified-regulation), and .89 (intrinsic-regulation).

\subsubsection{Utrecht Work Engagement Scale (UWES)}

The Utrecht Work Engagement Scale (Schaufeli et al. 2002b) measures work-engagement, that is, the intensity of vigor and enthusiasm workers feel about their work (Schaufeli and Bakker 2009). The scale has been adapted and validated both for Portuguese (Schaufeli et al. 2002a) and Brazilian populations (Machado et al. 2014; Porto-Martins et al. 2013). It comprises three subscales: Vigor, Dedication and Absorption, comprising a total of 17 items. Responses to the UWES are given on a 7-point Likert scale from $0=$ 'Never' to $6=$ 'Always/Every day'. A sample item is 'I find the work that I do full of meaning and purpose'. In the current study, the Cronbach alpha coefficient for the global scale was .94 in the Portuguese sample, and .95 in the Brazilian sample. The three subscales' Cronbach alpha coefficients in the Portuguese sample were: .83 (vigor), .91 (dedication) and .84 (absorption); in the Brazilian sample were: .89 (vigor), .91 (dedication) and .83 (absorption).

\subsubsection{Copenhagen Burnout Inventory (CBI)}

The Copenhagen Burnout Inventory (Kristensen et al. 2005) measures burnout, that is, the intensity of psychological and physical fatigue or exhaustion a worker can 
experience at work (Kristensen et al. 2005). The CBI comprises three subscales: personal-burnout, work-related-burnout and client-related-burnout. In the current study, only the personal-burnout scale was used, composed of six items. We selected this scale because of the relevance of this type of burnout in relation to DW, and excluded other scales to avoid a long protocol. Response options are on a 5-point Likert scale, from $1=$ 'Always' to $5=$ 'Never/Almost Never'. One sample item is 'How often are you emotionally exhausted?'. In the present study, we used the scale adapted and validated both for Portuguese (Fonte 2011) and Brazilian populations (Bonafé et al. 2012; Campos et al. 2013). The alpha coefficient in the current study was .89 in the Portuguese sample, and .91 in the Brazilian sample.

\section{Results}

We present the results in two main parts. In the first, given the various dimensions of constructs, we applied canonical correlation analysis to examine relationships between the seven DW factors and WM, work-engagement and burnout. In the second, we examine zero-order correlations results between DW global score and autonomous regulation (intrinsic and identified) and amotivation for both samples. All analyses were carried out in parallel for the Portuguese and Brazilian samples, allowing for replication and for the study of cross-cultural differences.

\subsection{Decent Work, Work-Motivation, Work-Engagement and Burnout}

\subsubsection{Canonical Correlations}

To study the relationship among the seven factors of DW, six types of work-motivation, three dimensions of work-engagement and personal-burnout, a canonical correlation analysis (CCA) was carried out. This kind of analysis is the most indicated in situations where multiple dependent and independent variables are simultaneously observed (Hair Jr et al. 1998). In the current study, the DW factors were considered as the set of independent variables (or the predictor set), while the set of dependent variables (or the criteria set) comprised all other variables (Kuylen and Verhallen 1981). Despite the infrequent use of CCA, its application is important in minimizing the Type I error rate, by simultaneously analyzing the two sets of variables rather than examining a large number of individual correlations (Sherry and Henson 2005). Our analyses were carried out using IBM SPSS Statistics version 22, with the help of STATS CANCORR (an extension bundle from IBM SPSS, installed as part of IBM SPSS Statistics - Essentials for Python; IBM, 2016). To interpret significant canonical functions, we opted for the canonical loadings approach. This procedure involves examining the magnitude and sign of the structure's canonical coefficients (also known as canonical loadings) found in canonical variate (Hair Jr et al. 1998; Dattalo 2014). This analysis allowed us to explore the underlying relations between DW Factors and types of WM, workengagement and personal-burnout. The results can be found in Tables 2 and 4 for the Portuguese sample, and 3 and 5 for the Brazilian sample.

For the Portuguese sample, three significant canonical functions were produced. For the Brazilian sample, two canonical functions were produced. For all functions, the 
Table 2 Results of canonical correlation analysis of the relationships of DW factors, levels of workmotivation, dimensions of work-engagement and personal-burnout for the Portuguese sample $(n=300)$

\begin{tabular}{lllllll}
\hline Canonical function & $\mathrm{R}_{\mathrm{c}}$ & $\mathrm{R}_{\mathrm{c}}^{2}$ & Wilks's Lambda & $\mathrm{F}$ & $\mathrm{R}_{\mathrm{dx}}$ & $\mathrm{R}_{\mathrm{dy}}$ \\
\hline 1 & .70 & .49 & .30 & $5.52^{* * *}$ & .20 & .15 \\
2 & .52 & .27 & .58 & $3.05^{* * *}$ & .04 & .03 \\
3 & .32 & .10 & .79 & $1.69^{* *}$ & .01 & .01 \\
\hline
\end{tabular}

$* \rho<.05 ; * * \rho<.01 ; * * * \rho<.001$

$R_{c}$ overall canonical correlation; $R_{c}{ }^{2}$ overall squared canonical correlation; $R_{d x}$ redundancy index of set of dependent variables given the canonical variate for DW factors; $R_{d y}$ redundancy index of DW factors given the canonical variate for the dependent variables

correlation between the linear composites (canonical variates) created for each of the variable sets, that is, the canonical correlations $\left(R_{C}\right)$, attains non-trivial values (above .30, as recommended by Pituch and Stevens 2016).

To establish the relevance of our canonical functions, we used other statistical indicators. According to Sherry and Henson (2005), Wilks's $\lambda$ "represents the variance unexplained by the model, and thus $1-\lambda$ yields the full model effect size" (p. 48). In the Portuguese sample, the Wilks's $\lambda$ value indicates that the full model explains $70 \%$ of the variance shared between the two variable set. In the Brazilian sample, it explains $71 \%$ of the shared variance. Considering each canonical function, for the Portuguese sample, the first canonical function explains approximately $61 \%$ of the shared explained variance, with the second canonical function explaining another $24 \%$, and the third canonical function adding 7\%. These three canonical functions therefore accumulate approximately $92 \%$ of the explained variance. For the Brazilian sample, the first canonical function accounts for more than $64 \%$ of the shared variance, with the second canonical function explaining more than $24 \%$. These two canonical functions together accumulate more than $88 \%$ of the explained variance (values based on eigenvalues; Meyers et al. 2013). For each set of variables, for the Portuguese sample, DW factors explained $49 \%$ of the variance of work-motivation, work-engagement and burnout (dependent set of variables) through the first canonical function, 27\% through the second, and approximately $10 \%$ through the third. For the Brazilian sample, DW factors explained $52 \%$ of the variance of the dependent set of variables through the first canonical function, and approximately $28 \%$ through the second (see Tables 2 and 3 , values based on $\mathrm{R}_{\mathrm{c}}{ }^{2}$, Meyers et al. 2013).

Table 3 Results of canonical correlation analysis of the relationships of DW factors, levels of workmotivation, dimensions of work-engagement and personal-burnout for the Brazilian sample $(\mathrm{n}=305)$

\begin{tabular}{lllllrr}
\hline Canonical function & $\mathrm{R}_{\mathrm{c}}$ & $\mathrm{R}_{\mathrm{c}}{ }^{2}$ & Wilks's Lambda & $\mathrm{F}$ & $\mathrm{R}_{\mathrm{dx}}$ & $\mathrm{R}_{\mathrm{dy}}$ \\
\hline 1 & .72 & .52 & .29 & $5.69 * * *$ & .16 & .20 \\
2 & .53 & .28 & .60 & $2.91 * * *$ & .05 & .03 \\
\hline
\end{tabular}

$* \rho<.05 ; * * \rho<.01 ; * * * \rho<.001$

$R_{c}$ overall canonical correlation; $R_{c}{ }^{2}$ overall squared canonical correlation; $R_{d x}$ redundancy index of set of dependent variables given the canonical variate for DW factors; $R_{d y}$ redundancy index of DW factors given the canonical variate for the dependent variables 
These results suggest that the relationships between decent work dimensions and work-motivation, work-engagement and burnout are explained by three main mechanisms, in the Portuguese sample, and by two in the Brazilian sample, upon which interpretation of the canonical variate should throw light.

In Tables 4 and 5, we present the canonical variates, the corresponding standardized coefficients (canonical weights), structure coefficients (canonical loadings) and cross loadings associated with each variable. The standardized coefficients are the optimized weights of the DW factors and of the set of dependent variables in the estimation of canonical variates, whereas the correlations of these linear combinations with each variable are represented by the structure coefficients. Although there is no consensus among authors about the most adequate coefficients to consider in interpreting canonical variates, we have decided to follow Hair Jr et al. (1998) advice, and based our interpretation on the highest values of the structure coefficients (Meyers et al. 2013). Although Tabachnick and Fidell (2014) suggest the use of a threshold of .30, we opted to use a more conservative value of .45 (following Joo and Nimon 2014), closer to common practice in factor analysis.

In the Portuguese sample, the first canonical function shows that all the DW factors correlate strongly and in the same direction with identified and intrinsic motivation, and with all three work-engagement dimensions, suggesting that work contexts in which DW is felt promote more autonomous motivations (identified and intrinsic) and all aspects of work-engagement (vigor, dedication and absorption). In addition, high DW work contexts also seem to minimize personal-burnout. In other words, the absence or lack of the DW factors seems to contribute to decreasing work-engagement and increasing burnout.

In the Brazilian sample, regarding the first canonical function, the DW factors Fundamental-principles-and-values-at-work (DW1), Adequate-working-time-andworkload (DW2), Fulfilling-and-productive-work (DW3) and Opportunities (DW6) correlate strongly and positively with identified and intrinsic motivation, vigor, dedication and absorption, and strongly and negatively with amotivation and personal-burnout. For the Brazilian physicians, therefore, these four DW factors, more than others, are related to the avoidance of amotivation and burnout and promotion of vigor, dedication and absorption, and more autonomous types of motivation (identified and intrinsic).

The second canonical functions are preponderantly themed around Adequate-Working-Time-and-Workload (DW2). For the Portuguese sample, a strong negative correlation with identified WM and burnout is found. These results show that in work contexts where there are adequate working schedules and a reasonable workload, identified motivation and personal-burnout are lower.

In the Brazilian sample, the second canonical correlation is a little different. Adequate-working-time-and-workload (DW2) and Social-protection (DW5) show strong inverse relationships with personal-burnout. This means that in professional situations in which working hours and workloads are excessive and the physician feels a lack of social protection, personal burnout tends to be developed.

There was a third canonical function for the Portuguese sample and it brought together the lack of Meaningful-remuneration-for-the-exercise-of-citizenship (DW4) and the lack of extrinsic-social and material-motivations, in a positive direction (an unexpected finding). 
تृّี

อ.

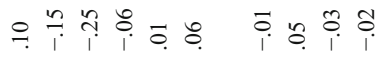

它实

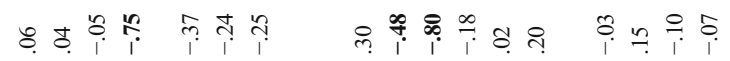

还峞

กิ่

कก ๆ

ฐ્च

总|

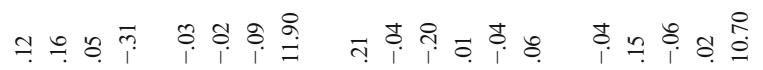

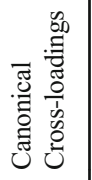

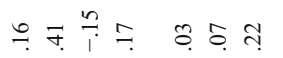

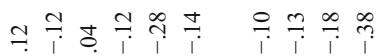

莺 焉

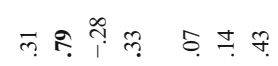

4⿻ำ

密宽

ㄲํํำㅇำ

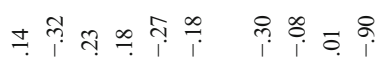

तี่

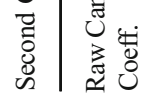

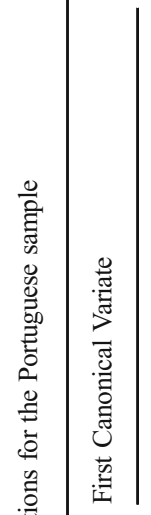

تृ.

范

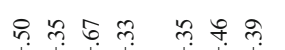

$\bar{m}$

造

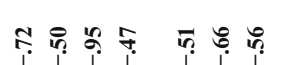

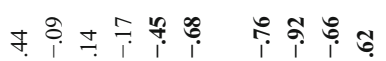

密发

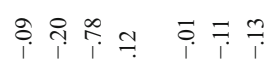

$\Rightarrow \frac{1}{8} \div$

$\infty \stackrel{0}{0}:$ :

芯

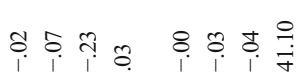

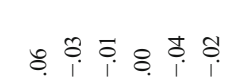

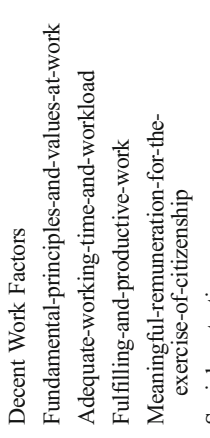

$5 \frac{m}{1} 0 \frac{0}{m}$

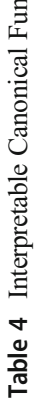

(a) 


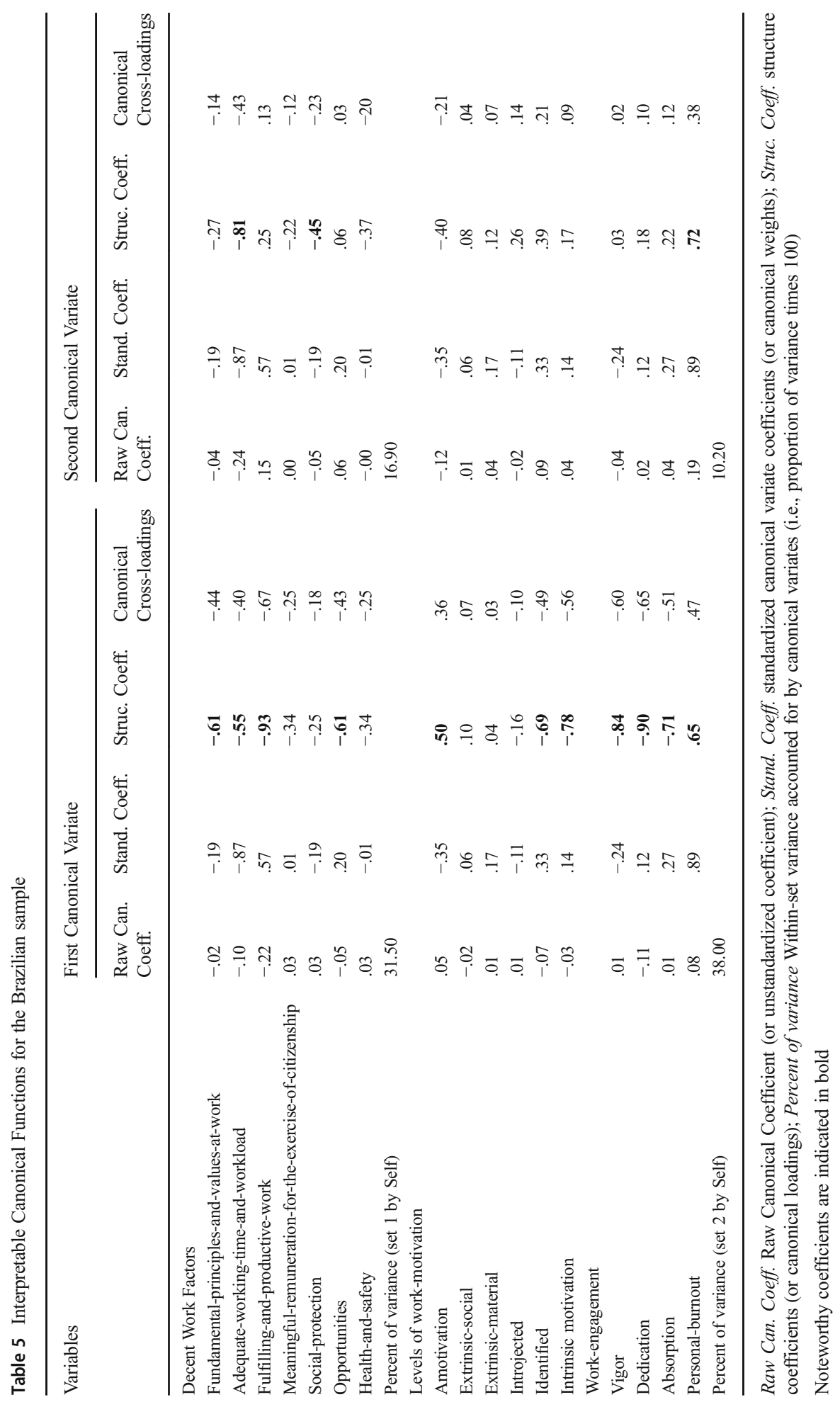


The non-existence of this third canonical correlation in the Brazilian sample suggests that for the physicians in this sample there appears to be no relationship between Meaningful remuneration and WM, or work-engagement or burnout.

\subsubsection{Zero-Order Correlations}

These assertions were reinforced with analysis of zero-order correlations (whose results are available and can be requested to the authors) and support $\mathrm{H} 1$ and $\mathrm{H} 2$ in the two samples. For the Portuguese sample, the correlation between Global DW and intrinsic WM was .33 (significant at the .01 level). The correlation between Global DW and Identified WM was .17 (also significant at the .01 level) and the result for amotivation $(-.26)$ in $\mathrm{H} 2$ was also significant at the .01 level. For the Brazilian sample, the correlation between Global DW and intrinsic WM was .36 (significant at the .01 level). The correlation between Global DW and Identified WM was .27 (also significant at the .01 level) and the correlation between Global DW and amotivation was -.17 (also significant at the .01 level) in H2. In both samples, the Global DW were related significantly and positively with the more self-determined types of work-motivation (intrinsic and identified; H1); and significantly and negatively with the lack of workmotivation (amotivation; H2).

\section{Discussion and Conclusions}

\subsection{Findings}

The study showed that DW issues have an important role in promoting physicians' more autonomous work-motivations (identified and intrinsic), making a very important contribution to producing work-engagement (vigor, dedication and absorption) and to avoiding personal-burnout. Purohit and Bandyopadhyay (2014) discuss the importance of better understanding of doctors' motivations to enable better management of the healthcare workplace and provision of quality healthcare. Some facets of DW seem to play a more important role in these regards. Global DW and the more autonomous types of motivation are strongly related. However, the relationships between Global DW and vigor, dedication and absorption are even stronger. The inverted interaction between Global DW and personal-burnout is also high. From a WOPP perspective, these three results are very important because they suggest the potential of DW as a predictor of more autonomous work-motivations, work-engagement and as a concept relevant for preventing burnout. In sum, considering the DW facets when approaching work design seems to increase work performance and physicians' well-being.

The DW factors of Fulfilling-and-productive-work, Fundamental-principles-andvalues-at-work and Opportunities seem to have a remarkable role on WM, workengagement and personal-burnout (see the first canonical correlation). The perception of work as fulfilling and productive in the worker's current professional context has a highlighted role in the effect observed.

The role of Adequate-working-time-and-workload in our samples became clearer in the second canonical correlation. Despite the difference in this correlation involving other facets of DW (social-protection in the Brazilian sample) and identified motivation 
(in the Portuguese sample), the main result is that excessive working hours and/or workload contribute to the development of burnout. Probably, for the Portuguese sample, in work situations with excessive working hours and workload, identified motivation may function as a protection, and physicians may develop personal-burnout but they remain working by taking into account the relevance of the work they perform. For the Brazilian sample, it seems that a deficit of adequate working time, workload and social protection contribute to development of burnout. Adequate time and workload management might be a strategy to protect these workers from burnout.

Only for the Portuguese sample, a third canonical function appears, involving Meaningful-remuneration-for-the-exercise-of-citizenship and extrinsic-social and material-motivations. Perception of low Meaningful-remuneration-for-the-exercise-of-citizenship was related to low extrinsic-material-motivation and low extrinsic-socialmotivation. Several interpretations are possible. Meaningful remunerations (or compensations) as proposed in DWQ is related to the interface between a life lived with autonomy and dignity and the compensation (or rewards) received for work, the possibility to feel personal well-being from earnings received at work and being a provider of well-being for those who depend on the worker, and the perception of fairness regarding earnings. Portuguese physicians seem to associate the lack of Meaningful remuneration with the lack of extrinsic (social-and-material) motivations. Physicians are highly qualified professionals, with a high educational level, and can expect to be well compensated for the great dedication required in their work. Nantha (2013) highlights the lack of studies on promoting physicians' intrinsic workmotivation and the emphasis on extrinsic motivation studies. This author states that despite the positive effects observed with the implementation of practices of external rewards, "physicians often reach a plateau in their desire for financial incentives after several years of practice" (p. 268). In the Portuguese sample, the third canonical correlation related to remuneration or compensation system might be an effect of age, taking into account that most Portuguese professionals in the sample are 2135 years old. In a study carried out in Portugal in partnership with the 'Ordem dos Médicos' (Portuguese Medical Association), Vala et al. (2016) sought to characterize the medical class in Portugal regarding burnout. They found in the age group of up to 35 years, the highest level of depersonalization and decreased personal fulfillment, this group also presenting the greatest emotional exhaustion. Maslach and Jackson (1981) affirmed that "burnout is likely to occur within the first few years of one's career" (p.111). Maslach (2003) also states that burnout tends to be higher in younger workers. According to Vala et al. (2016), it is precisely this younger age group, at the beginning of the career, when professionals work as 'interns' and have fewer years of practice, which presented lower satisfaction with remuneration and perceived lower stability in employment, considered factors with predictive values of higher levels of emotional exhaustion. According to Chaix-Couturier et al. (2000), the effectiveness of the use of financial incentives depends on "the target set for a given health care programme" (p. 133). Marshall and Harrison (2005) argued that some professionals (such as health professionals) have an internal 'moral' motivation: "a force which encourages people to behave in ways which have no obvious advantages to the individual and may even prove contrary to their interests" (p. 5). Some health professionals 'go the extra mile' with or for their patients without thinking about financial rewards (p. 5). Arnetz (2001) affirms that for some medical professionals the core of their work is the physician- 
patient relationship, which is the source of gratifying experience and "one of the most severe emotional risk factors" (p. 205). Considering this, perhaps the Portuguese sample participants expect to be well compensated both materially and socially, and these expectations were not being met for the younger Portuguese physicians at the time data was collected.

Considering our sample composed of physicians, the lack of effect of Health-andsafety maybe seen as paradoxical, but that is not the case. Rimpela et al. (1987) argued that doctors do not apply their professional skills and knowledge to reduce their own mortality. As aforementioned, the professional group of physicians is known for the low attention given to their own health. Indeed, this can explain the lower loading (< .45) of the Health-and-safety results for the Brazilian sample in the two canonical functions, for example.

The presence of Global DW was positively related to intrinsic and identified WM as well as work-engagement (positive and healthy aspects of well-being). In our study, the deficit of Global DW and Adequate-working-time-and-workload (DW2), Fundamentalprinciples-and-values-at-work (DW1) and Fulfilling-and-productive-work (DW3) were related to the development of personal-burnout.

The antecedents of work-engagement and burnout have been widely studied (Alarcon 2011; Alarcon et al. 2009; Lee and Ashforth 1996; Bakker et al. 2008, 2014; Christian et al. 2011; Mache et al. 2014; Mauno et al. 2007; Schaufeli and Bakker 2004). However, we consider that the recent studies of DW can bring contributions to better understanding of these two concepts and also demonstrate their own importance for Work Psychology research.

According to Bakker et al. (2014), while many burnout predictors are related to job demands, the antecedents of work-engagement are related to job resources. The present study aligns with this when finding that DW is positively associated with more autonomous WM and work-engagement, and that DW is negatively related to amotivation and burnout.

The main findings of our study suggest that Global DW (and the seven DW factors) highlighting Fulfilling-and-productive-work, Fundamental-principles-and-values-atwork and Opportunities can be predictors of work-engagement. The deficit of Adequate-working-time-and-workload can play a role as an antecedent of burnout.

\subsection{Implications}

The third canonical correlation, only in the Portuguese sample, suggests that the issue of reward systems in healthcare deserves more research, particularly the role of DW contexts as predictors of extrinsic motivation. At an organizational level, important cultural aspects may interfere with this theme. Empirical studies applying measures of organizational culture that consider medical culture and national culture could bring important results regarding the antecedents and consequences of appropriately designed reward systems in healthcare systems. At an individual level, the relationship among personal values, medical professional values, and work-related context values could shed light on the balance between extrinsic and intrinsic types of work-motivation, as well as on increased work-engagement.

HR management can play a relevant role in promoting work-motivation, workengagement and avoidance of burnout. The application of a DW approach in 
conceiving strategic HR interventions can promote innovative/creative work/job (re)design, which besides promoting improvements in work/job quality, do so by taking into account the principles and values applied to the work based on ongoing dialogue with all involved (Ferraro et al. 2015).

To promote work-motivation, Gagné and Deci (2005) suggest it is possible to use job/work design (Hackman and Oldham 1976; Oldham and Hackman 2010), including (re)design of reward systems and other management practices, to satisfy the psychological needs to be competent, autonomous and to relate to others and promote autonomous regulation. Adequate job design should be meaningful and stimulating (job enrichment). Applied to medical work and settings, considering job enrichment as empowering workers to have more decision-making autonomy over their own work can be a good way to motivate physicians; or training in the use of new technologies (more below). Interventions aimed at developing physicians' qualifications for leadership and management functions can also contribute to greater satisfaction and motivation of doctors and multifunctional teams (McAlearney et al. 2005).

Schaufeli et al. (2009) recommend organizational and individual-based interventions to decrease burnout in health care, such as job-redesign (with specific focus on tackling stress and burnout) and stress prevention and management training. Improvements in working-time-arrangements are good strategies but any solution that involves time management needs to be tailored to different DW contexts. The same physician may work in a private practice, keep shiftwork schedules in different hospitals and still provide care in a clinic or hospital that provides public services. Although it is possible to suggest flexible work schedules (as in Schaufeli and Bakker 2004), flexibility does not seem to be exactly the most complex factor in the time aspect. Excessive working hours (overtime) with excessive emotional load (over-workload), and possible sleep deprivation associated with an exchange of schedules and/or institutions where the profession is exercised appear to be the most aggravating factors for the health of physicians.

\subsection{Limitations and Recommendations for Future Research}

Studies about doctors as KW are not common. More studies dedicated to investigating various concepts of WOPP, especially work motivations and physicians' well-being as KW, can make major contributions to physicians' professional activities and for management in healthcare settings. Future studies with samples from other countries and/or with larger samples according to medical speciality, may also bring relevant new information.

In another direction, new studies devoted to other types of KW will enable us to understand DW's relationship with the motivation and well-being of these professional groups. A better understanding of DW contexts for all workers is important. But considering the growing number of $\mathrm{KW}$ in the global workforce, understanding the DW contexts of these professionals can be a real need for anyone wishing to act in strategic HR in the near future.

Our study did not measure organizational level variables, organizational culture or HR policies and practices and their peculiarities in doctor management. In the future, these types of measures may contribute to more clarity about the role of decent work in the performance and well-being of physicians. 
At the individual level, we suggest that further studies be carried out aimed at the doctor's motivation to work (based on SDT). In this sense, despite the medical profession being essentially dedicated to caring for people (patient-centric focus; McAlearney et al. 2005; Heikkila et al. 2015) and requiring all physicians' technical and personal skills, there seem to be more studies on extrinsic motivations (monetary or not) than on intrinsic motivations, associated with personal and professional values. More studies considering the balance of these motivations will surely make major contributions to the profession.

Studies on work-engagement and burnout seem to move towards specialization according to the medical speciality. There are pros and cons in this trend. The advantages lie in knowing very specific situations in detail, and perhaps it is possible to develop and implement techniques and strategies that are well adapted to these situations. On the other hand, more specificity is harder to generalize and therefore to transform the tools and resources developed into generalizable ones applicable to policies and practices in other contexts. Despite the attention to nomological aspects of operationalization of a concept being closer to scientific propositions, this does not make idiosyncratic aspects any less relevant. Research on idiosyncrasies can lead to nomological findings (and vice versa).

At the societal level, in any society better understanding of a professional category's performance with possibilities for improving performance and increasing productivity in groups/organizations is relevant. The role of doctors in communities' healthcare systems and the population's health is fundamental for people's quality of life.

The development of studies that seek to improve understanding of the workmotivation and well-being of these workers and promote them corresponds to investing in improving their quality of working life and is therefore, a way to invest in people's quality of life. Taking into account the variables studied, we consider the need for further studies with other designs that allow interpretations regarding causality (a limitation of cross-sectional study design). A longitudinal study to evaluate DW over time (as suggested by Bescond et al. 2003; ILO 2008), as well as fluctuations in motivation, work-engagement and/or burnout is a possibility. Dyrbye et al. (2013) made a cross-sectional study on the relationship between 'physician satisfaction and burnout at different career stages' (p. 1358). Their findings suggest that further studies are needed so that they can follow career development and fluctuations in other variables. Longitudinal studies may also contribute to evaluating the perception of DW at the beginning of the medical career and over time, with the accumulation of professional experience.

Finally, as mentioned above, the use of a cross-sectional design in the present study restricts the possibility of causal inferences. The use of a self-report survey has also known limitations. For further research, qualitative research and the cited longitudinal data collection can bring more information about causal mechanisms and the variations of DW, WM, Work engagement and Burnout in physicians over time. This could bring relevant results to enrich our understanding of our set of variables.

\subsection{Conclusion}

The SDT and the concept of well-being are deeply related to a humanistic conception of the human being (Gagné and Vansteenkiste 2013), which is also central in Positive 
Psychology (Bohart and Greening 2001; Seligman and Csikszentmihalyi 2000). Positive Psychology proposes to rescue and promote the optimal aspects of human functioning (Joseph and Linley 2004).

The DW approach is a new area of research and the role of decent work as a potential causal element in a network of other WOPP concepts still warrants many empirical studies. We believe that DW is a concept with quite universal characteristics that should be tested in different work-settings. Future empirical studies testing DW relations with different known variables in WOPP and its role as a precursor of health and well-being at the workplace need to be developed. Our study suggests that, for the doctors in our samples, DW contributes to the promotion of identified and intrinsic motivation, work-engagement and to avoiding burnout.

Acknowledgments This study was supported in part by grant from the Coordenação de Aperfeiçoamento de Pessoal de Nível Superior (CAPES), Ministry of Education of Brazil, Brasília, DF, Brazil (CAPES fellow, Process $\mathrm{N}^{\circ}$ BEX 9703/13-6).

\section{Compliance with Ethical Standards}

Conflict of Interest The authors declare that there is no conflict of interests with respect to the research, authorship, and/or publication of this article.

\section{References}

Alarcon, G. (2011). A meta-analysis of burnout with job demands, resources, and attitudes. J Vocat Behav, $79(2), 549-562$.

Alarcon, G., Eschleman, K. J., \& Bowling, N. A. (2009). Relationships between personality variables and burnout: A meta-analysis. Work \& Stress, 23, 244-263.

Anagnostopoulos, F., Liolios, E., Persefonis, G., Slater, J., Kafetsios, K., \& Niakas, D. (2012). Physician burnout and patient satisfaction with consultation in primary health care settings: Evidence of relationships from a one-with-many design. J Clin Psychol Med Settings, 19, 401-410.

Arnetz, B. B. (2001). Psychosocial challenges facing physicians of today. Soc Sci Med, 52, 203-213.

Baard, P. P., Deci, E. L., \& Ryan, R. M. (2004). Intrinsic need satisfaction: A motivational basis of performance and well-being in two work settings. J Appl Soc Psychol, 34(10), 2045-2068.

Bakker, A. B., \& Schaufeli, W. B. (2008). Positive organizational behavior: Engaged employees in flourishing organizations. J Organ Behav, 29, 147-154.

Bakker, A. B., Schaufeli, W. B., Leiter, M. P., \& Taris, T. W. (2008). Work engagement: An emerging concept in occupational health psychology. Work \& Stress, 22(3), 187-200.

Bakker, A. B., Demerouti, E., \& Sanz-Vergel, A. I. (2014). Burnout and work engagement: The JD-R approach. Annual Review of Organizational Psychology and Organizational Behavior, 1, 389-411.

Bescond, D., Châtaignier, A., \& Mehran, F. (2003). Seven indicators to measure decent work: An international comparison. International Labour Review, 142(2), 179-211.

Bohart, A. C., \& Greening, T. (2001). Humanistic psychology and positive psychology. Am Psychol, 56(1), 81-82.

Bonafé, F. S. S., Trotta, O. S. T., Maroco, J., \& Campos, J. A. D. B. (2012). Burnout: Desconhecido pela comunidade, mas prevalente entre dentistas. Revista Paulista de Odontologia, 34(2), 36-41.

Borritz, M., Rugulies, R., Bjorner, J. B., Villadsen, E., Mikkelsen, O. A., \& Kristensen, T. S. (2006). Burnout among employees in human service work: Design and baseline findings of the PUMA study. Scandinavian Journal of Public Health, 34, 49-58.

Bowden, M. J., Mukherjee, S., Williams, L. K., DeGraves, W. S., Jackson, M., \& McCarthy, M. C. (2015). Work-related stress and reward: An Australian study of multidisciplinary pediatric oncology healthcare providers. Psycho-Oncology, 24, 1432-1438. 
Caesens, G., Stinglhamber, F., \& Luypaert, G. (2014). The impact of work engagement and workaholism on well-being: The role of work-related social support. Career Dev Int, 19(7), 813-835.

Cameron, K. S., \& Caza, A. (2004). Introduction: Contributions to the discipline of positive organizational scholarship. Am Behav Sci, 47(6), 731-739.

Campos, J. A. D. B., Carlotto, M. S., \& Maroco, J. (2013). Copenhagen burnout inventory - student version: Adaptation and transcultural validation for Portugal and Brazil. Psicologia Reflexão $e$ Crítica, 26(2), 87-97.

Casqueira, C. M. S. C. (2018). Decent work, toxic leadership and work motivation: an empirical research with workers (unpublished master thesis). Coimbra: Universidade de Coimbra.

Chaix-Couturier, C., Durand-Zaleski, I., Jolly, D., \& Durieux, P. (2000). Effects of financial incentives on medical practice: Results from a systematic review of the literature and methodological issues. Int J Qual Health Care, 12(2), 133-142.

Christian, M. S., Garza, A. S., \& Slaughter, J. E. (2011). Work engagement: A quantitative review and test of its relations with task and contextual performance. Pers Psychol, 64, 89-136.

Cropanzano, R., Rupp, D. E., \& Byrne, Z. S. (2003). The relationship of emotional exhaustion to work attitudes, job performance, and organizational citizenship behaviors. J Appl Psychol, 88, 160-169.

Dattalo, P. V. (2014). A demonstration of canonical correlation analysis with orthogonal rotation to facilitate interpretation. School of Social Work, Virginia Commonwealth University, Richmond, Virginia: Unpublished manuscript.

Dos Santos, N.R., Mónico, L., Pais, L., Gagné, M., Forest, J., Cabral, P.M.F., \& Ferraro, T. (2018). Multidimensional Work Motivation Scale: Psychometric studies in Portugal and Brazil. Manuscript submitted for publication.

Dyrbye, L. N., Varkey, P., Boone, S. L., Satele, D. V., Sloan, J. A., \& Shanafelt, T. D. (2013). Physician satisfaction and burnout at different career stages. Mayo Clinical Proceedings, 88(12), 1358-1367.

Ferraro, T., Pais, L., \& dos Santos, N. R. (2015). Decent work: An aim for all made by all. International Journal of Social Sciences, IV(3), 30-42. https://doi.org/10.20472/SS2015.4.3003.

Ferraro, T., dos Santos, N. R., Pais, L., \& Mónico, L. (2016). Historical landmarks of decent work. European Journal of Applied Business and Management, 2(1), 77-96.

Ferraro, T., dos Santos, N. R., Pais, L., \& Moreira, J. M. (2017). Decent work and work motivation in lawyers: An empirical research. Revista Psicologia Organizações e Trabalho, 17(4), 192-200. https://doi. org/10.17652/rpot/2017.4.13908.

Ferraro, T., Moreira, J. M., dos Santos, N. R., Pais, L., \& Sedmak, C. (2018a). Decent work, work motivation and psychological capital: An empirical research. Work: A Journal of Prevention, Assessment, and Rehabilitation, 60(2), 339-354. https://doi.org/10.3233/WOR-182732.

Ferraro, T., Pais, L., dos Santos, N. R., \& Moreira, J. M. (2018b). The decent work questionnaire (DWQ): Development and a validation in two samples of knowledge workers. International Labour Review, 157(2), 243-265. https://doi.org/10.1111/ilr.12039.

Fonte, C.M.S. (2011). Adaptação e Validação para Português do Questionário de Copenhagen Burnout Inventory (CBI) (master thesis).Coimbra: Universidade de Coimbra. Retrieved from EstudoGeral: <https://estudogeral.sib.uc.pt/bitstream/10316/18118/1/Adapta\%C3\%A7\%C3\%A3o\%20e\%20 Valida\%C3\%A7\%C3\%A3o\%20para\%20Portugu\%C3\%AAs\%20do\%20Questin\%C3\%A1rio\%20 de\%20Copen.PDF>,

Gagné, M., \& Deci, E. L. (2005). Self-determination theory and work motivation. J Organ Behav, 26, 331-362.

Gagné, M., \& Vansteenkiste, M. (2013). Self-determination theory's contribution to positive organizational psychology. In A. B. Bakker (Ed.). Advances in Positive Organizational Psychology (pp. 61-62), vol. 1. Bingley, UK: Emerald.

Gagné, M., Forest, J., Vansteenkiste, M., Crevier-Braud, L., Van den Broeck, A., Aspeli, A. K., et al. (2015). The multidimensional work motivation scale: Validation evidence in seven languages and nine countries. European Journal of Work and Organizational Psychology, 24(2), 178-196.

Garcia, H. A., McGeary, C. A., Finley, E. P., Ketchum, N. S., McGeary, D. D., \& Peterson, A. L. (2015). Burnout among psychiatrists in the veterans health administration. Burn Res, 2, 108-114.

Hackman, J. R., \& Oldham, G. R. (1976). Motivation through the design of work: Test of a theory. Organizational Behavior and Human Performance, 16, 250-279.

Hair Jr., J. F., Anderson, R. E., Tatham, R. L., \& Black, W. C. (1998). Multivariate data analysis. New Jersey, USA: Prentice-Hall International.

Heikkila, T. J., Hyppölä, H., Vänskä, J., Aine, T., Halila, H., Kujala, S., et al. (2015). Factors important in the choice of a medical career: A Finnish national study. BMC Medical Education, 15, 169-176. 
International Business Machines (IBM) Corporation (2016). Extension bundles from IBM SPSS. USA: IBM Corporation. Available from: https:/www.ibm.com/developerworks/community/files/form/anonymous/api/library/b5 bb8a42-04d2-4503-93bb-dc45d7a145c2/document/1d445b76-d706-44a6-85bf-9e3738d223a4 /media/Extension\%20Commands\%20from\%20IBM\%20SPSS.pdf

International Labour Organization. (1944). Declaration concerning the aims and purposes of the International Labour Organisation (Philadelphia declaration). In Conférence Internationale du Travail, $26^{\text {th }}$ session. Philadelphia, USA: International Labour Office.

International Labour Organization. (1999). Decent Work: Report of the director-general at $87^{\text {th }}$ session of international labour conference. Geneva: International Labour Office.

International Labour Organization. (2008). Decent work: Some strategic challenges ahead. In International labour conference, 97th session, report of the director-general. Geneva: International Labour Office.

Joo, B.-K., \& Nimon, K. (2014). Two of a kind? A canonical correlational study of transformational leadership and authentic leadership. European Journal of Training and Development, 38(6), 570-587.

Joseph, S., \& Linley, P. A. (2004). Applied positive psychology: A new perspective for professional practice. In P. A. Linley \& S. Joseph (Eds.), Positive psychology in practice (pp. 3-12). New Jersey: John Wiley \& Sons, Inc..

Kamal, A. H., Bull, J. H., Wolf, S. P., Swetz, K. M., Shanafelt, T. D., Ast, K., et al. (2016). Prevalence and predictors of burnout among hospice and palliative care clinicians in the U.S. J Pain Symptom Manag, 51(4), 690-696.

Kassam, A., Horton, J., Shoimer, I., \& Patten, S. (2015). Predictors of well-being in resident physicians: A descriptive and psychometric study. Journal of Graduate Medical Education, 7(1), 70-74.

Kristensen, T. S., Borritz, M., Villadsen, E., \& Christensen, K. B. (2005). The Copenhagen burnout inventory: A new tool for the assessment of burnout. Work \& Stress, 19(3), 192-207.

Kuylen, A. A. A., \& Verhallen, T. M. M. (1981). The use of canonical analysis. J Econ Psychol, 1, $217-237$.

Lee, R. T., \& Ashforth, B. E. (1996). A meta-analytic examination of the correlates of the three dimensions of job burnout. Journal of Applied Psychology, 81(2), 123-133.

Lindgren, A., Baathe, F., \& Dellve, L. (2013). Why risk professional fulfillment: A grounded theory of physician engagement in healthcare development. Int J Health Plann Manag, 28, e138-e157.

Luthans, F. (2002a). Positive organizational behavior: Developing and maintaining psychological strengths. Acad Manag Exec, 16(1), 57-72.

Luthans, F. (2002b). The need for and meaning of positive organizational behavior. J Organ Behav, 23, 695706.

Luthans, F., \& Avolio, B. J. (2009). The "point” of positive organizational behavior. J Organ Behav, 30, 291307.

Luthans, F., \& Youssef, C. M. (2007). Emerging positive organizational behavior. J Manag, 33(3), 321-349.

Machado, P. G. B., Porto-Martins, P. C., \& Benevides-Pereira, A. M. T. (2014). Engagement no trabalho em profissionais de uma empresa de transporte público urbano. Psicologia Argumento, 32(79), 175-185.

Mache, S., Vitzthum, K., Klapp, B. E., \& Danzer, G. (2014). Surgeons' work engagement: Influencing factors and relations to job and life satisfaction. The Surgeon: Journal of the Royal Colleges of Surgeons of Edinburgh and Ireland, 12(4), 181-190.

Marshall, M., \& Harrison, S. (2005). It's about more than money: Financial incentives and internal motivation. British Medical Journal (BMJ) Quality \& Safety Health Care: The International Journal of Healthcare Improvement, 14, 4-5.

Maslach, C. (2003). Job burnout: New directions in research and intervention. Curr Dir Psychol Sci, 12(5), 189-192.

Maslach, C., \& Jackson, S. E. (1981). The measurement of experienced burnout. J Occup Behav, 2, $99-113$.

Maslach, C., Leiter, M. P., \& Schaufeli, W. B. (2008). Measuring burnout. In C. L. Cooper \& S. Cartwright (Eds.), The Oxford handbook of organizational wellbeing (pp. 86-108). Oxford: Oxford University Press.

Mathauer, I., \& Imhoff, I. (2006). Health worker motivation in Africa: The role of non-financial incentives and human resource management tools. Hum Resour Health, 4, $24-40$.

Mauno, S., Kinnunen, U., \& Ruokolainen, M. (2007). Job demands and resources as antecedents of work engagement: A longitudinal study. J Vocat Behav, 70, 149-171.

McAlearney, A. S., Fischer, D., Heiser, K., Robbins, D., \& Kelleher, K. (2005). Developing effective physician leaders: Changing cultures and transforming organizations. Hospital Topics: Research and Perspectives on Healthcare, 83(2), 11-18.

Meyers, L. S., Gamst, G., \& Guarino, A. J. (2013). Applied multivariate research: Design and interpretation. USA: SAGE.

Milfont, T. L., Denny, S., Ameratunga, S., Robinson, E., \& Merry, S. (2008). Burnout and wellbeing: Testing the Copenhagen burnout inventory in New Zealand teachers. Soc Indic Res, 89(1), 169-177. 
Misfeldt, R., Linder, J., Lait, J., Hepp, S., Armitage, G., Jackson, K., \& Suter, E. (2014). Incentives for improving human resource outcomes in health care: Overview of reviews. Journal of Health Services Research \& Policy, 19(1), 52-61.

Mládková, L., Zouharová, J., \& Nový, J. (2015). Motivation and knowledge workers. Procedia - Social and Behavioral Sciences, 207, 768-776.

Nantha, Y. S. (2013). Intrinsic motivation: How can it play a pivotal role in changing clinician behaviour? Journal of Health Organization and Management, 27(2), 266-272.

Oldham, G. R., \& Hackman, J. R. (2010). Not what it was and not what it will be: The future of job design research. J Organ Behav, 31, 463-479.

Pituch, K. A., \& Stevens, J. P. (2016). Applied multivariate statistics for the social science: Analyses with SAS and IBM's SPSS. New York, NY: Routledge.

Porto-Martins, P. C., Machado, P. G. B., \& Benevides-Pereira, A. M. T. (2013). Engagement no trabalho: uma discussão teórica. Fractal, 25(4), 629-644.

Prins, J. T., Gazendam-Donofrio, S. T., Tubben, B. J., van der Heijden, F. M. M. A., van de Wiell, H. B. M., \& Hoekstra-Weebers, J. E. H. M. (2007). Burnout in medical residents: A review. Med Educ, 41, 788-800.

Purohit, B., \& Bandyopadhyay, T. (2014). Beyond job security and money: Driving factors of motivation for government doctors in India. Hum Resour Health, 12, 1-12.

Rimpela, A. H., Nurminen, M. M., Pukkinen, P. O., Rimpela, M. K., \& Valkonen, T. (1987). Mortality of doctors: Do doctors benefit from their medical knowledge? Lancet, 1(8524), 84-86.

Rodrigues, A. F. (2018). Decent work, work motivation and orientation to happiness: a profile analysis (unpublished master thesis). Coimbra: Universidade de Coimbra.

Rowe, A. K., Savigny, D., Lanata, C. F., \& Victora, C. G. (2005). How can we achieve and maintain highquality performance of health workers in low-resource settings? Lancet, 366, 1026-1035.

Schaufeli, W. B., \& Bakker, A. B. (2004). Job demands, job resources, and their relationship with burnout and engagement: A multi-sample study. J Organ Behav, 25(3), 293-315.

Schaufeli, W.B., \& Bakker, A.B. (2009). The Utrecht Work Engagement Scale-Test manual (R. angst, A. M. T. Benevides-Pereira, \& P. C. Porto-Martins, trad.). Utrecht: Department of Social \& organizational psychology. (original manual published in 2003).

Schaufeli, W. B., \& Taris, T. W. (2005). The conceptualization and measurement of burnout: Common ground and worlds apart. Work \& Stress, 19(3), 256-262.

Schaufeli, W. B., Martínez, I. M., Pinto, A. M., Salanova, M., \& Bakker, A. B. (2002a). Burnout and engagement in university students: A cross-national study. J Cross-Cult Psychol, 33(5), 464-481.

Schaufeli, W. B., Salanova, M., González-Romá, V., \& Bakker, A. B. (2002b). The measurement of engagement and burnout: A two sample confirmatory factor analytic approach. J Happiness Stud, 3(1), 71-92.

Schaufeli, W. B., Taris, T. W., \& van Rhenen, W. (2008). Workaholism, burnout, and work engagement: Three of a kind or three different kinds of employee well-being? Applied Psychology: An International Review, 57(2), 173-203.

Schaufeli, W. B., Bakker, A. B., der Heijden, F. M. M. A., \& Prins, J. T. (2009). Workaholism, burnout and well-being among junior doctors: The mediating role of role conflict. Work \& Stress, 23(2), 155-172.

Schaufeli, W. B., Maassen, G. H., Bakker, A. B., \& Sixma, H. J. (2011). Stability and change in burnout: A 10-yearfollow-up study among primary care physicians. J Occup Organ Psychol, 84, 248-267.

Schaufeli, W. B., Dijkstra, P., \& Vazquez, A. C. (2013). Engajamento no trabalho. São Paulo: Casa do Psicólogo.

Seligman, M. E. P., \& Csikszentmihalyi, M. (2000). Positive psychology. Am Psychol, 55(1), 5-14.

Shanafelt, T. D., Balch, C. M., Bechamps, G., Russell, T., Dyrbye, L., Satele, D., et al. (2010). Burnout and medical errors among American surgeons. Ann Surg, 251(6), 1-6.

Sheldon, K. M., \& Ryan, R. M. (2011). Positive psychology and self-determination theory: A natural interface. In V. I. Chirkov, R. M. Ryan, \& K. M. Sheldon (Eds.), Cross-cultural advancements in positive psychology: Human autonomy in cross-cultural context: Perspectives on the psychology of agency, freedom, and well-being (pp. 33-44). Dordrecht, NLD: Springer.

Sherry, A., \& Henson, R. K. (2005). Conducting and interpreting canonical correlation analysis in personality research: A user-friendly primer. J Pers Assess, 84(1), 37-48.

Shirom, A., Nirel, N., \& Vinokur, A. D. (2006). Overload, autonomy, and burnout as predictors of physicians' quality of care. J Occup Health Psychol, 11(4), 328-342.

Tabachnick, B. G., \& Fidell, L. S. (2014). Using multivariate statistics (6th ed.). London: Pearson.

Treaty of Peace between the Allied and Associated Powers and Germany. (1919). Treaty of Versailles, 28 June. France: Versailles. 
United Nations (2000). UN Global Compact: The ten principles. Brochure. Retrieved from http://www. unglobalcompact.org/AboutTheGC/TheTenPrinciples/index.html

United Nations (2015). Transforming our world: the 2030 Agenda for Sustainable Development. Resolution adopted by the general assembly on 25 September 2015 (A/RES/70/1). 69 ${ }^{\text {th }}$ session of UN general assembly. New York: United Nations. Retrieved from http://www.un.org/ga/search/view_doc. asp?symbol=A/RES/70/1\&Lang=E

Vala, J. (Coord.), Pinto, A. M., Moreira, S., \& Lopes, R. C. (2016). Burnout na classe médica: Estudo nacional, principais resultados. Lisboa: Ordem dos Médicos. Retrieved from http://www.dependencias. pt/ficheiros/conteudos/files/Burnout.pdf

Webster, E., Budlender, D., \& Orkin, M. (2016). Developing a diagnostic tool and policy instrument for the realization of decent work. International Labour Review, 154(2), 123-145.

Wen, J., Cheng, Y., Hu, X., Yuan, P., Hao, T., \& Shi, Y. (2016). Workload, burnout, and medical mistakes among physicians in China: A cross-sectional study. BioScience Trends, 10(1), 27-33.

Willis-Shattuck, M., Bidwell, P., Thomas, S., Wyness, L., Blaauw, D., \& Ditlopo, P. (2008). Motivation and retention of health workers in developing countries: A systematic review. BioMed Central Health Services Research, 8, 247-254.

Wright, T. A. (2003). Positive organizational behavior: An idea whose time has truly come. J Organ Behav, 24(4), 437-442.

Publisher's Note Springer Nature remains neutral with regard to jurisdictional claims in published maps and institutional affiliations.

\section{Affiliations}

\section{Tânia Ferraro $^{1}$ - Nuno Rebelo dos Santos ${ }^{2}$ • João Manuel Moreira ${ }^{3} \cdot$ Leonor Pais $^{1}$}

Nuno Rebelo dos Santos

nrs@uevora.pt

João Manuel Moreira

joao.moreira@campus.ul.pt

Leonor Pais

leonorpais@fpce.uc.pt

1 Faculty of Psychology and Educational Sciences, University of Coimbra, Coimbra, Portugal, FPCE, Rua do Colégio Novo, S/N, 3000-115 Coimbra, Portugal

2 Escola de Ciências Sociais, Évora, Portugal, Departamento de Psicologia, Universidade de Évora, Largo dos Colegiais, 2, 7004-516 Évora, Portugal

3 Faculty of Psychology, Lisbon, Portugal, Alameda da Universidade, University of Lisbon, 1649-

013 Lisbon, Portugal 